\title{
TEORES DE MACRONUTRIENTES EM MUDAS DE ACEROLEIRA (Malpighia emarginata DC.) EM FUNÇÃO DA COMPOSIÇÃO DO SUBSTRATO
}

\author{
Macronutrients content in barbados cherry seedlings as a function of \\ sources and levels of organic matter in the substrate
}

\author{
Rosiane de Lourdes Silva de Lima ${ }^{1}$, Dalmo Lopes de Siqueira ${ }^{2}$, \\ Olmar Baller Weber ${ }^{3}$, Paulo Roberto Cecon ${ }^{2}$
}

\begin{abstract}
RESUMO
A composição do substrato com diferentes fontes de matéria orgânica é considerado como um elemento chave na obtenção de mudas de boa qualidade. Assim, com este estudo objetivou-se avaliar a melhor fonte e a melhor quantidade de matéria orgânica que poderá ser usada para a produção de mudas de aceroleira (Malpighia emarginata DC.) de boa qualidade. Um fatorial quatro (20:80, 40:60, 60:40 e 80:20\% de matéria orgânica:terra) por quatro (húmus de minhoca, casca de arroz carbonizada, pó de casca de coco seco e bagana de carnaubeira) níveis foi usado em delineamento em blocos casualizados com quatro repetições. O conteúdo de nitrogênio, fósforo, potássio e cálcio nas folhas e caules foram quantificados na matéria seca das mudas. Os resultados demonstraram que a proporção de $80 \%$ de húmus: $20 \%$ de terra permitiram bom desenvolvimento das plantas com níveis suficientes de N, P, K e Ca. Casca de arroz carbonizada, pó de casca de coco seco e bagana de carnaubeira não contribuíram para a obtenção de mudas de boa qualidade.
\end{abstract}

Termos para indexação: Malpighia emarginata, estaquia, substratos, matéria orgânica.

\section{ABSTRACT}

The composition of substrates with different sources of organic matter is considered as a key factor to obtain seedlings of good quality. Then, this study aimed to evaluate the best source and the best quantity of organic matter that should be used in order to produce barbados cherry (Malpighia emarginata DC.) seedlings of good quality. A factorial arrangement of four (20:80, 40:60, 60:40 and 80:20\% of organic matter:earth) by four (earthworm compost, burnt rice husk, powdered coconut husk and carnauba straw) levels was used and it was designed in randomized blocks with four replicates. The nitrogen, phosphorus, potassium and calcium content of the leaves and stems were quantified in the dry tissue. The results showed that the proportion $80 \%$ of earthworm compost: $20 \%$ of earth allowed good development of the plants and sufficient accumulation of N, P, K and Ca. Burnt rice husk, powdered coconut husk and carnauba straw have not generated seedlings of good quality.

Index terms: Malpighia emarginata, cutting, substrate, organic matter.

(Recebido para publicação em 18 de janeiro de 2005 e aprovado em 18 de julho de 2006)

\section{INTRODUÇÃO}

A produção de mudas de aceroleira (Malpighia emarginata DC.), utilizando sementes ou estacas de ramos do ano, não é uma técnica nova nessa cultura. Entretanto, com o surgimento de novos materiais clonais, o uso da estaquia vem crescendo. Uma das principais dificuldades para implementação dessa técnica tem sido o manejo dos substratos, isso devido à exigência de adaptação dos viveiros ao novo paradigma de substituição do solo por substratos para a produção comercial das mudas.

Materiais tais como pó de casca de coco (CORRÊA et al., 2003), esterco bovino (ANDRADE NETO et al., 1999), casca de arroz carbonizada (GOMES et al., 2000), e húmus de minhoca (LIMA et al., 2003) tem sido utilizados na formulação de substratos em misturas com terra, enriquecida ou não com fertilizantes químicos para a produção de mudas de diversas espécies frutíferas. Para a produção de mudas de aceroleira, Corrêa et al. (2002) recomendam como substrato o uso de terra enriquecida com adubo fosfatado, na forma de superfosfato triplo, e zinco, na forma de sulfato de zinco. Por outro lado, para a produção de mudas por estaquia Lima et al. (2006) recomendam o uso de substratos compostos por misturas de $60 \%$ de húmus e $40 \%$ de casca de arroz carbonizada.

$\mathrm{Na}$ escolha do substrato, devem-se observar, principalmente, suas características físicas e químicas, a espécie a ser plantada, além dos aspectos econômicos, quais seja: baixo custo e grande disponibilidade. A esse respeito, Negreiros et al. (2004) salientaram a conveniência da associação de materiais orgânicos, especialmente em mistura com o solo, para melhorar a textura do substrato e, dessa maneira, propiciar boas condições físicas e fornecer os nutrientes necessários ao desenvolvimento das raízes e da muda.

'Engenheira Agrônoma, doutoranda em Agronomia,Produção Vegetal/Unesp - Jaboticabal, SP - limarosiane@yahoo.com.br ${ }^{2}$ Professor Adjunto, D.Sc., Departamentos de Fitotecnia e Matemática da Universidade Federal de Viçosa/UFV - 36571-000 - Viçosa, MG Siqueira@ufv.br.

${ }^{3}$ Engenheiro Agrônomo, D.Sc., Embrapa Agroindústria Tropical - Av. Dra. Sara Mesquita, 2270 - Pici - 60511-110 - Fortaleza, CE weber@cnpat.embrapa.br. 
Neste sentido, o conhecimento dos efeitos da composição do substrato nos teores foliares e caulinares de aceroleira poderá auxiliar a escolha da fonte e da dose de matéria orgânica a ser utilizada para compor substratos para a produção de mudas por estaquia.

Este trabalho teve como objetivo medir os teores foliares e caulinares de nutrientes em mudas de aceroleira cultivadas em diferentes composições de substrato.

\section{MATERIAL E MÉTODOS}

O experimento foi conduzido em casa-de-vegetação com sistema de nebulização intermitente da Embrapa Agroindústria Tropical, em Fortaleza, CE, no período de novembro de 2001 a janeiro de 2002.

Para a produção das mudas foram utilizadas estacas caulinares semilenhosas, provenientes de plantas matrizes da progênie P-91 com 3,5 anos de idade, cultivada no jardim clonal do Campo Experimental da Embrapa em Pacajus, CE.

Após a coleta dos ramos da mediana da copa das árvores, os mesmos foram acondicionados em recipientes com água e transportados para o laboratório. Retiraram-se 25 estacas provenientes da parte mediana do caule, descartando o ápice e a base, removendo o excesso de folhas, deixando um (1) par de folhas com $50 \%$ de área foliar. As estacas foram padronizadas em $12 \mathrm{~cm}$ de comprimento, utilizando-se um corte em bisel, próximo a uma gema, na base, e horizontal na parte superior. Em seguida, a parte basal das estacas foi imersa em solução de Benomyl a 0,2\%, e em solução de AIB (ácido indolbutírico) a $2000 \mathrm{mg} / \mathrm{mL}^{-1}$, conforme Lima et al. (1992).

$\mathrm{O}$ experimento em fatorial $4 \times 4$ (doses $\mathrm{x}$ fontes de matéria orgânica) foi conduzido em delineamento em blocos ao acaso, com 4 repetições e 10 plantas na parcela. A dose de matéria orgânica e terra foi representada por 4 níveis (20, 40, 60 e $80 \%)$. Foram usadas quatro fontes de matéria orgânica, (húmus, casca de arroz carbonizada, pó de casca de coco e bagana de carnaubeira). A composição química dos materiais orgânicos utilizados para compor os substratos encontra-se na Tabela 1.

Após 60 dias, em casa-de-vegetação, a parte aérea das mudas (folhas e caules) foi seca em estufa de circulação forçada a $65^{\circ} \mathrm{C}$ até peso constante. Posteriormente, as folhas foram separadas das estacas, moídas em moinho tipo Willey, passados em peneira de malha de 20 mesh,e submetidas à digestão nítrico-perclórica para determinar 0 teor de N, P, K e Ca nas folhas e caules das mudas. Para a determinação do teor de $\mathrm{N}$, as amostras foram submetidas à digestão sulfúrica. $\mathrm{O} \mathrm{N}$ foi dosado pelo método colorimétrico de Nessler (JACSON, 1958), o P pelo método da redução do fotomolibdato pela vitamina $\mathrm{C}$, modificado por Braga \& Defelipo (1974), o K por fotometria de chama e o Ca, por espectrofotometria de absorção atômica.

TABELA 1 - Características químicas dos materiais húmus de minhoca $(\mathrm{H})$, casca de arroz carbonizada (CAC), pó de casca de coco (PCC) e bagana de carnaubeira (BC) utilizados nos tubetes para a formação de mudas de aceroleira.

\begin{tabular}{lcccc}
\hline \multirow{2}{*}{ Características } & \multicolumn{4}{c}{ Fontes de matéria orgânica } \\
\cline { 2 - 5 } & $\mathbf{H}$ & CAC & PCC & BC \\
\hline $\mathrm{pH}$ em água $(1: 2,5)$ & 6,5 & 7,0 & 6,2 & 5,1 \\
$\mathrm{Al}\left(\mathrm{cmol}_{\mathrm{c}} / \mathrm{dm}^{3}\right)$ & 0,3 & 0,1 & 0,0 & 0,1 \\
$\mathrm{H}+\mathrm{Al}\left(\mathrm{cmol}_{\mathrm{c}} / \mathrm{dm}^{3}\right)$ & 2,8 & 0 & 1,4 & 5,4 \\
$\mathrm{P}\left(\mathrm{mg} / \mathrm{dm}^{3}\right)$ & 386,6 & 104,0 & 20,0 & 20,6 \\
$\mathrm{~K}\left(\mathrm{mg} / \mathrm{dm}^{3}\right)$ & 445 & 490 & 60 & 235 \\
$\mathrm{Ca}\left(\mathrm{mg} / \mathrm{dm}^{3}\right)$ & 12,6 & 0,5 & 0,7 & 4,7 \\
$\mathrm{Mg}\left(\mathrm{mg} / \mathrm{dm}^{3}\right)$ & 7,2 & 0,5 & 1,0 & 2,0 \\
$\mathrm{Na}\left(\mathrm{mg} / \mathrm{dm}^{3}\right)$ & 235 & 37 & 89 & 17 \\
$\mathrm{Fe}\left(\mathrm{mg} / \mathrm{dm}^{3}\right)$ & 21,8 & 11,4 & 16,2 & 23,2 \\
$\mathrm{Zn}\left(\mathrm{mg} / \mathrm{dm}^{3}\right)$ & 11,2 & 2,2 & 4,1 & 1,1 \\
$\mathrm{Mn}\left(\mathrm{mg} / \mathrm{dm}^{3}\right)$ & 12,3 & 8,0 & 2,0 & 23,5 \\
$\mathrm{Cu}\left(\mathrm{mg} / \mathrm{dm}^{3}\right)$ & 2,3 & 0,7 & 0,0 & 0,1 \\
\hline
\end{tabular}


Os dados obtidos foram submetidos à análise de variância, regressão e teste de Tukey, ao nível de 5\% de probabilidade, segundo Ferreira (1996).

\section{RESULTADOS E DISCUSSÃO}

Os teores foliares e caulinares de $\mathrm{N}$ variaram, consideravelmente, de acordo com a composição do substrato e da dose aplicada, observando-se teores máximos de $33,4 \mathrm{~g} \mathrm{~kg}^{-1}$ nas folhas e de $15 \mathrm{~g} \cdot \mathrm{kg}^{-1}$ no caule de mudas de aceroleira cultivadas em substrato contendo húmus, e mínimos de $19 \mathrm{~g} \mathrm{~kg}^{-1}$ na folha e $6,0 \mathrm{~g}^{\mathrm{kg}} \mathrm{kg}^{-1}$ no caule naquelas cultivadas em substrato contendo CAC, PCCS e $\mathrm{BC}$, respectivamente (Figura 1).

A aplicação de húmus à composição do substrato promoveu acréscimo significativo nos teores foliares e caulinares de N, observando-se que, à medida que se aumentou a proporção desta fonte de matéria orgânica em relação a terra ocorreu um aumento nos teores foliares e caulinares de $\mathrm{N}$ nas mudas. Como o húmus é uma fonte de matéria orgânica rica em nitrogênio (Tabela 1) e de baixa relação $\mathrm{C} / \mathrm{N}$, o $\mathrm{N}$ mineralizado pode ser absorvido pelas mudas, contribuindo satisfatoriamente para a manutenção de teores elevados de $\mathrm{N}$ nos tecidos da planta. Por outro lado, a aplicação de CAC, PCCS e BC à composição do substrato pouco influenciaram os teores foliares de N. Possivelmente, uma das explicações para estes resultados pode ser creditada à elevada relação $\mathrm{C} /$ $\mathrm{N}$ destes materiais. $\mathrm{O}$ teor de $\mathrm{N}$ observado nas folhas e caules das mudas de aceroleira cultivadas em substrato contendo húmus encontram-se na faixa dos considerados adequados por Fernandes et al. (2000) em mudas de

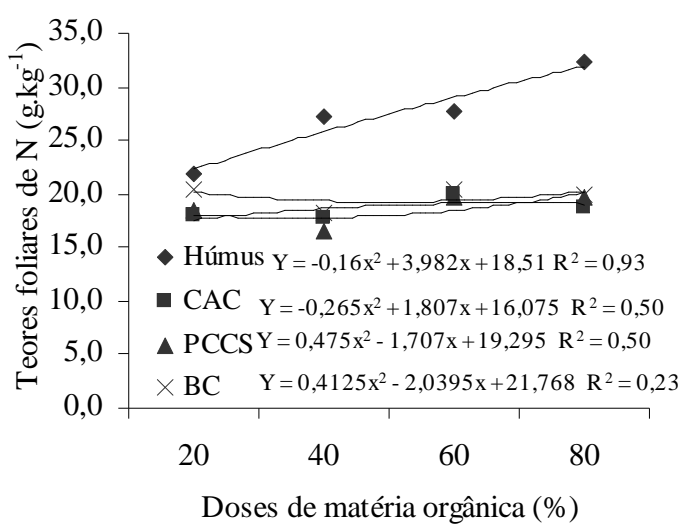

aceroleira da mesma espécie conduzidas em sistema hidropônico $\left(27,2 \mathrm{~g} \cdot \mathrm{kg}^{-1}\right.$ para tecidos foliares e $11,6 \mathrm{~g} \cdot \mathrm{kg}^{-1}$ para tecidos caulinares). Contudo, os teores observados nos substratos contendo CAC, PCCS e BC encontram-se abaixo daqueles considerados adequados para folhas por Jones Júnior et al. (1991) que são de 20 g.kg ${ }^{-1}$ a 35 g.kg ${ }^{-1}$ e por Silva (1998) que consideram teores caulinares adequados àqueles que se situam na ordem de $13 \mathrm{~g} . \mathrm{kg}^{-1}$ de N.

Os teores foliares de $\mathrm{P} \mathrm{e} \mathrm{K}$ (Figura 2) variaram em função da fonte de matéria orgânica utilizada. Maiores teores de $\mathrm{P}$ e $\mathrm{K}$ foram observados em mudas cultivadas em substrato contendo húmus e CAC em sua composição, e menores nos substratos contendo BC. Teores de $\mathrm{P} \mathrm{e} \mathrm{K}$ da ordem de $1,8 \mathrm{~g} \cdot \mathrm{kg}^{-1}$ e $40 \mathrm{~g} \cdot \mathrm{kg}^{-1}$ foram constatados no substrato contendo húmus em sua composição. Por outro lado, os menores foram observados em tecidos foliares de mudas cultivadas em substrato contendo PCCS e BC. Os teores de $\mathrm{P}$ e $\mathrm{K}$ obtidos neste trabalho encontram-se dentro da faixa de valores considerada como adequada por Fernandes et al. (2000) $\left(1,40\right.$ g. $\mathrm{kg}^{-1}$ e 41,6 g. $\left.\mathrm{kg}^{-1}\right) \mathrm{em}$ mudas de M. emarginata cultivadas em soluções nutritiva e por Amaral (1998) em plantas de acerola com dois anos no campo.

No caule, os teores de $\mathrm{P}$ e $\mathrm{K}$ variaram amplamente em função da composição do substrato (Figura 3) e das doses aplicadas. Maiores teores de $\mathrm{P}$ foram constatados no tecido caulinar de mudas cultivadas em substrato contendo húmus $\left(1,5 \mathrm{~g} \cdot \mathrm{kg}^{-1}\right)$ e os menores $\left(0,9 \mathrm{~g} \cdot \mathrm{kg}^{-1}\right)$ foram obtidos em mudas cultivadas em substrato contendo $\mathrm{CAC}$, PCCS e $\mathrm{BC}$, os quais não diferiram estatisticamente.

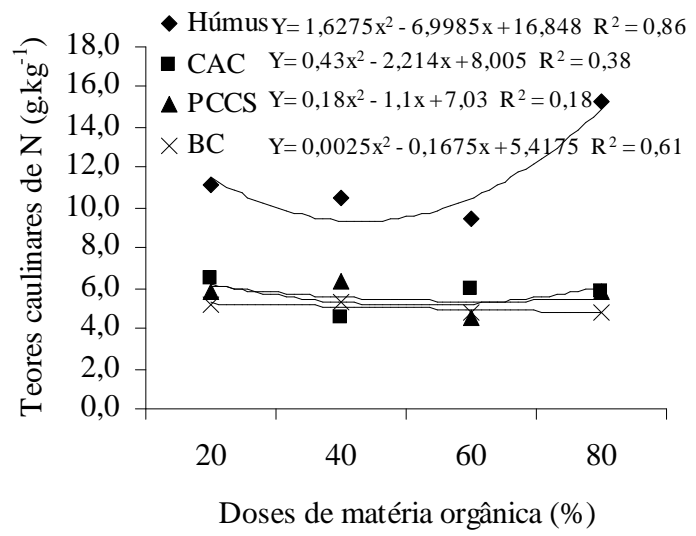

FIGURA 1 - Teores foliares e caulinares de nitrogênio $\left(\mathrm{g} \cdot \mathrm{kg}^{-1}\right)$ em mudas de aceroleira em função de fontes e doses de matéria orgânica. Fortaleza, CE, 2002.

Ciênc. agrotec., Lavras, v. 30, n. 6, p. 1110-1115, nov./dez., 2006 

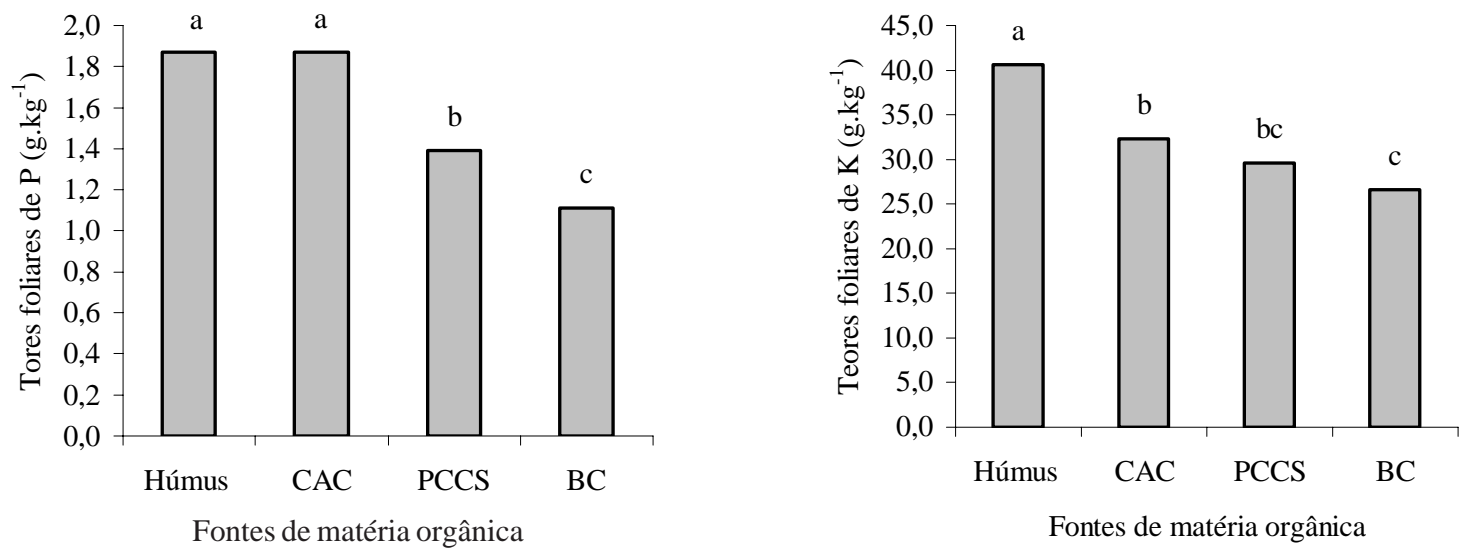

FIGURA 2 - Teores foliares de fósforo e potássio $\left(\right.$ g. $\left.\mathrm{kg}^{-1}\right)$ em mudas de progênies de aceroleira em função de fontes de matéria orgânica. Médias de duas progênies. Fortaleza, CE, 2002.
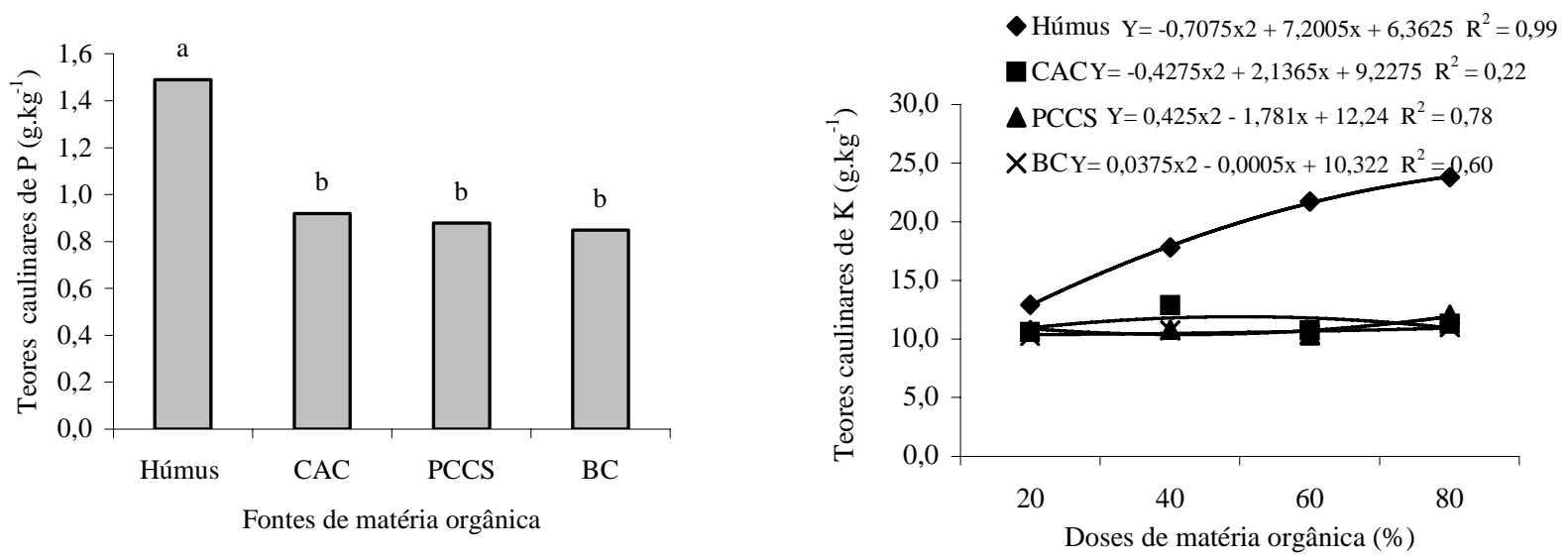

FIGURA 3 - Teores caulinares de fósforo e potássio $\left(\mathrm{g} \cdot \mathrm{kg}^{-1}\right)$ em mudas de aceroleira em função de fontes e doses de matéria orgânica. Fortaleza, CE, 2002.

Por outro lado, os teores caulinares de K foram influenciados pelas doses e pelas fontes de matéria orgânica estudadas, obtendo-se teores máximos $\left(24\right.$ g. $\left.\mathrm{kg}^{-1}\right)$ deste nutriente quando se aplicou $80 \%$ de húmus em mistura com $20 \%$ de terra, e mínimo (10 g.kg-1 $)$ em substratos contendo CAC, PCCS e BC, os quais foram similares em todas as doses utilizadas. Os teores de $\mathrm{P}$ e $\mathrm{K}$ observados nas mudas cultivadas em substrato contendo húmus encontram-se dentro da faixa considerada adequada por Fernandes et al. (2000) para mudas de aceroleira cultivadas em solução nutritiva e Silva (1998) que encontrou em plantas adequadamente nutridas a concentração de 1,9 g. $\mathrm{kg}^{-1}$ de P e de 16,5 g. $\mathrm{kg}^{-1}$ de $\mathrm{K}$ em plantas de aceroleira com 120 dias em condições de campo.

Era esperado que materiais ricos em $\mathrm{P}$ e $\mathrm{K}$ propiciassem condições favoráveis para que ocorresse maior acúmulo deste nutriente na planta. No entanto não há uma relação direta entre concentração do nutriente no material orgânico e teores na matéria seca da planta, visto que a CAC apresentava em sua composição química teores elevados de $\mathrm{P}$ e de $\mathrm{K}$, e a BC teores elevados de $\mathrm{K}$. Provavelmente, a disponibilidade deste nutriente no substrato não tenha interferido nos teores caulinares deste elemento, visto que o tempo de permanência das mudas no substrato foi muito curto. Por outro lado, a emissão de primórdios radiculares pelas estacas podem ter reduzido a concentração de P e K nos tecidos da planta, independente do meio de cultivo.

Quanto ao Ca foliar e caulinar, observando-se a Figura 4, constata-se que houve efeito de fonte e de dose para o Ca foliar e de apenas fonte de matéria orgânica para o Ca caulinar. Teores foliares máximos de Ca $\left(26,8\right.$ g. $\left.\mathrm{kg}^{-1}\right)$ 

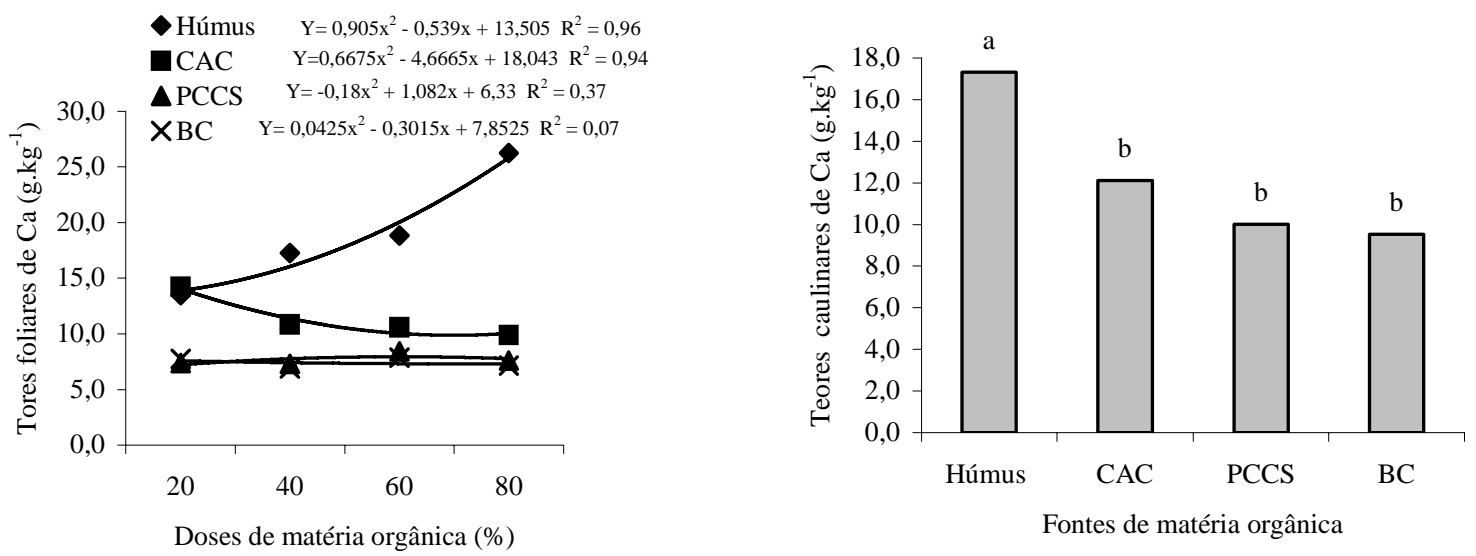

FIGURA 4 - Teores foliares e caulinares de Cálcio $\left(\mathrm{g}^{\mathrm{kg}} \mathrm{kg}^{-1}\right)$ em mudas de aceroleira em função de fontes e doses de matéria orgânica. Fortaleza, CE, 2002.

foram obtidos quando se utilizou 80\% de húmus em mistura com $20 \%$ de terra, para compor o substrato, e os menores $\left(6\right.$ g. $\left.\mathrm{kg}^{-1}\right)$ foram detectados quando se aplicou BC, PCCS ou BC. Os teores de Ca observados nas folhas das mudas cultivadas nos substratos contendo BC, PCCS e BC encontram-se abaixo dos valores obtidos por Fernandes et al. (2000) em mudas cultivadas em solução nutritiva, que foram de $16,4 \mathrm{~g} . \mathrm{kg}^{-1}$.

No caule, os teores de Ca diferiram significativamente em função da composição do substrato. Menores teores de Ca $\left(9,0\right.$ g. $\left.\mathrm{kg}^{-1}\right)$ foram observados no substrato contendo PCCS e BC, que diferiram significativamente do substrato contendo húmus $(17,0$ g. $\left.\mathrm{kg}^{-1}\right)$. Os teores observados neste trabalho encontramse acima dos observados por Fernandes et al. (2000) (12,1 g.kg-1) e Jones Júnior et al. (1991).

\section{CONCLUSÕES}

A aplicação de húmus à composição do substrato propiciou condições adequadas para a obtenção de mudas com teores foliares e caulinares satisfatórios de N, P, K e Ca.

Mudas cultivadas em substrato contendo casca de arroz carbonizada, pó de casca de coco seco e bagana de carnaubeira não contribuíram satisfatoriamente para a obtenção de mudas de boa qualidade.

\section{REFERÊNCIASBIBLIOGRÁFICAS}

AMARAL, J. F. T. Parte da planta e época para diagnose do estado nutricional e crescimento de ramos em aceroleira (Malpighia emarginata D.C). 1998. 84 f. Dissertação (Mestrado) - Universidade Federal de Viçosa, Viçosa, 1998.
ANDRADE NETO, A.; MENDES, A. N. G.; GUIMARÃES, P. T. G. Avaliação de substratos alternativos e tipos de adubação para a produção de mudas de cafeeiro (Coffea arábica L.) em tubetes. Ciência e Agrotecnologia, Lavras, v. 23, n. 2, p. 270-280, 1999.

BRAGA，J. M.; DEFELIPO, B. Determinação espectrofotométrica de fósforo em extratos de solos e plantas. Revista Ceres, Viçosa, v. 21, p. 73-85, 1974.

CORRÊA, F. L. de O.; SOUZA, C. A. S.; CARVALHO, J. G.; MENDONÇA, V. Fósforo e zinco no desenvolvimento de mudas de aceroleira. Revista Brasileira de Fruticultura, v. 24, n. 3, p. 793-796, 2002.

CORRÊA, F. L. de. O.; SOUZA, C. A. S.; MENDONÇA, V.; CARVALHO, J. G. de. Acúmulo de nutrientes em mudas de aceroleira adubadas com fósforo e zinco. Revista Brasileira de Fruticultura, Jaboticabal, v. 24, n. 3, p. 765-769, 2003.

FERNANDES, A. A.; SILVA, G. D.; MARTINEZ, H. E. P.; BRUCKNER, C. H. Sintomatologia das deficiências minerais e quantificação de macronutrientes em mudas de aceroleira. Revista Ceres, Viçosa, v. 47, n. 274, p. 639-650, 2000.

FERREIRA, P. V. Estatística experimental aplicada à agronomia. 2. ed. Maceió: Edufal, 1996. 606 p.

GOMES, J.E.; PERECIN, D.; MARTINS, A. B. G.; IGNÁCIO, N. Enraizamento de estacas herbáceas de genótipos de acerola em câmara de nebulização intermitente tratadas com ácido indolbutírico em duas épocas. Revista Brasileira de Fruticultura, Jaboticabal, v. 22, n. 3, p. 407-412, 2000. 
JACKSON, M. L. Nitrogen determinations for soil and plant tissue. In: Soil chemical analysis. Englewood Cliffs: Prentice-Hall, 1958. p. 183-204.

JONES JUNIOR, J. B.; WOLF, B.; MILL, H. A. Plant analysis handbook, a pratical samplig, preparation, analysis, and interpretation guide. Anthens: MicroMacro, 1991.

LIMA, A. C. S.; ALMEIDA, F. A. C.; ALMEIDA, F. C. G. Estudo sobre o enraizamento de estacas de acerola (Malpighia glaba L.). Revista Brasileira de Fruticultura, Cruz das Almas, v. 14, n. 1, p. 7-13, 1992.

LIMA, R. L. S.; FERNANDES, V. L. B.; OLIVEIRA, V. H.; HERNANDEZ, F. F. F. Acúmulo de N, K, Ca, Mg e S na matéria seca da parte aérea de mudas de cajueiro-anãoprecoce submetidas a níveis crescentes de matéria orgânica. Revista Brasileira de Fruticultura, Jaboticabal, v. 25, n. 1, p. 148-151, 2003.

LIMA, R. L. S.; SIQUEIRA, D. L.; WEBER, O. B.; CAZETTA, J. O. Comprimento de estacas e parte do ramo na formação de mudas de aceroleira. Revista Brasileira de Fruticultura, Jaboticabal, v. 28, n. 1, p. 83-86, 2006.

NEGREIROS, J. R. S.; BRAGA, L. R.; ÁLVARES, V. S.; BRUCKNER, C. H. Influência de substratos na formação de porta-enxerto de gravioleira (Anna muricata L.). Ciência e Agrotecnologia, Lavras, v. 28, n. 3, p. 530-536, 2004.

SILVA, G. D. Absorção de macronutrientes e micronutrientes pela aceroleira (Malpighia glaba $\mathbf{L}$.). 1998. 61 f. Dissertação (Mestrado) - Universidade Federal de Viçosa, Viçosa, 1998. 